\title{
The effect of differences in group
} composition on knowledge transfer, group \section{achievement, and learners' affective} responses during reciprocal concept mapping with the Kit-Build Approach

Lia Sadita ${ }^{1 *}$ (D), Tsukasa Hirashima ${ }^{1}$, Yusuke Hayashi ${ }^{1}$, Pedro G. F. Furtado ${ }^{1}$, Kasiyah Junus ${ }^{2}$ and Harry Budi Santoso ${ }^{2}$

*Correspondence:

lia@lel.hiroshima-u.ac.jp ${ }^{1}$ Learning Engineering Laboratory, Department of Information Engineering, Hiroshima University, Hiroshima, Japan

Full list of author information is available at the end of the article

\begin{abstract}
Collaborative learning requires a structured and open environment where individuals can actively exchange and elaborate their ideas to achieve a high-quality problem-solving solution. The use of concept map has been extensively implemented to facilitate idea generation and maintain shared focus during discussion. This study employs the Reciprocal Kit-Build (RKB) approach as a designed activity to support collaborative concept mapping. Though previous studies show the RKB is promising to promote productive discussion and achieve high-quality group products, they have not investigated how individual knowledge differences may potentially influence the effectiveness of collaboration. This study aims to identify the effect of group composition on learning effectiveness at the level of interaction between individual and group and at the level of the group as a whole. At the interaction level, we investigate the amount of knowledge transfer from shared and unshared individual knowledge to group solutions, while at the group level, the quality of collaborative maps is evaluated. Moreover, we explore the affective responses of learners during designated activities. A single group design is applied to illustrate the learning activities in a practical classroom settings where all students receive the same treatment. Our findings show that the transfer of individual shared and unshared knowledge is considerably high in all group conditions. Group composition does not significantly affect knowledge transfer and final group-outcome products; however, it may induce learners to experience different affective states. The results are essential for practitioners who intend to apply the RKB in their classroom to determine the appropriate group settings.
\end{abstract}

Keywords: Collaborative concept map, Concept map, Kit build, Knowledge convergence (c) The Author(s). 2020 Open Access This article is licensed under a Creative Commons Attribution 4.0 International License, which permits use, sharing, adaptation, distribution and reproduction in any medium or format, as long as you give appropriate credit to the original author(s) and the source, provide a link to the Creative Commons licence, and indicate if changes were made. The images or other third party material in this article are included in the article's Creative Commons licence, unless indicated otherwise in a credit line to the material. If material is not included in the article's Creative Commons licence and your intended use is not permitted by statutory regulation or exceeds the permitted use, you will need to obtain permission directly from the copyright holder. To view a copy of this licence, visit http://creativecommons.org/licenses/by/4.0/. 


\section{Introduction}

A central question of research and practice in computer-supported collaborative learning is how learners within a group influence each other and manage to converge regarding their knowledge (Fischer et al. 2002; Weinberger et al. 2007). Convergence of knowledge is defined as occurring when the activities of two or more learners have an impact on those of their partners, which impact their own activities in turn (Roschelle 1992). Jeong and Chi state that a similarity of knowledge may be achieved because group members experience the same environmental and cultural conditions or collaboratively interpret a situation or solve a problem together (Jeong and Chi 2007). We therefore believe that the design of a learning environment, including activities and tasks, is a critical factor in obtaining knowledge convergence following a collaborative session.

Preconceptions and divergence in knowledge influence the benefits experienced by group members when learning collaboratively (Weinberger and Fischer 2006). To promote the negotiation of perspectives towards shared understanding, prior studies on collaborative learning suggest the use of heterogeneous group composition (Weinberger et al. 2007; Johnson and Johnson 1987; Webb 2009). In a heterogeneous situation, we expected group members would constructively build on different ideas, thus promoting similarities of knowledge. While previous research confirms that nurturing group members to use available knowledge is beneficial in helping learners to attain knowledge convergence, unfortunately, it is also found that groups often neglect unshared resources-that is, knowledge and information that only a small number of the group possess or have access to (Fischer and Mandl 2002). This emphasizes the need for a structured and open collaborative-learning environment where individuals actively exchange, build, and elaborate the shared and unshared knowledge resources of the group.

In this study, we use a concept map as an external-representation tool of students' mental models (schemata). The concept map is a graphical structure that illustrates one's cognitive knowledge, consisting of concepts and the relationships between concepts (links) (Novak and Gowin 1984). Since individual knowledge structures (i.e., schemata or mental models) are not directly observable, an externalized representational tool is required to explain the complex phenomena of human learning, reasoning, and problemsolving (Ifenthaler 2010; Hirashima and Hayashi 2016). Manipulation of such external representation may promote sophistication of internal representation (learning). Hay, Kinchin, and Baker describe four important uses of concept mapping in higher education: to identify students' prior knowledge, to facilitate meaningful learning, to share knowledge and understanding between teachers and learners, and to detect learners' conceptual changes (Hay et al. 2008).

The concept map has been widely employed in collaboration to facilitate idea generation, maintain shared focus, and negotiate meaning (Basque and Lavoie 2006). Utilizing a concept map during collaboration supports the collaborative-learning process (i.e., knowledge elicitation and negotiation), since the cognitive structure of learners is made visible and ready to manipulate (Fischer and Mandl 2002). The use of a concept map to represent group-shared understanding has positively impacted learning achievements, both at individual and group level (Stoyanova and Kommers 2002). At the individual level, the concept map allows knowledge to become more explicit and provides room for reflection and elaboration of cognition (Stoyanova and Kommers 2002), while at the group level, the concept map promotes the establishment of common ground as a basis 
for building shared understanding among group members (Jeong and Hmelo-Silver 2016; Roschelle and Teasley 1995; Stoyanova and Kommers 2002). A concept map is an effective tool for the elicitation of knowledge and for communicating complex ideas (Fischer and Mandl 2002; Stoyanova and Kommers 2002; Suthers 2006; van Boxtel et al. 2000). Moreover, studies have found that collaborative concept mapping activity encourages students' positive attitudes, e.g., by increasing group motivation, reducing members' anxiety, and increasing students' responsibility for learning (Beers et al. 2006; Czerniak and Haney 1998; van Boxtel et al. 2002).

Though studies of collaborative concept maps show promising results, variations in learning activities have been encouraged to assist more productive interaction, such as including an individual-preparation phase or a sharing of the group members' concept maps before the collaborative session (Fischer and Mandl 2002; Engelmann and Hesse 2010). By adding the individual-preparation phase, each learner can develop their own understanding, which results in a better explanation of individual knowledge and more elaboration during discourse (Fischer and Mandl 2002; van Boxtel et al. 2000; Gracia-Moreno et al. 2017). Sharing partners' knowledge structures beforehand has successfully increased awareness of others' knowledge, causing learners to focus directly on different perspectives (Engelmann and Hesse 2010; Engelmann et al. 2014). Active reviewing of group members' initial maps positively affects the broadness of group solutions to problems (Stoyanova and Kommers 2002).

The current study has extended collaborative concept mapping with the kit-build (KB) method, a re-constructional concept mapping approach to assess common understanding between a teacher and their students (Hirashima et al. 2015; Hirashima 2019). The KB method allows students to create concept maps based on predefined map components that come from the teacher's map. During map construction, the learners need to find the concept map structure. After all students complete their maps, the KB system visualizes all map similarities and differences to the teacher. Concept-map evaluation can thereby be realized instantaneously; in consequence, both teacher and students receive immediate feedback. In classroom practice, the KB analyzer has been used to find learners' misconceptions and to improve the teacher's lesson plan for the subsequent class (Yoshida et al. 2013; Pailai et al. 2017). KB automatic assessment achieved almost the same level of validity as well-known concept map manual assessment methods (Wunnasri et al. 2018).

Standard KB practice involves interaction between a teacher and their students, who have different levels of expertise regarding the subject field. While many studies are concerned with the effect of the KB method on individual learning (Yoshida et al. 2013; Hirashima et al. 2015; Pailai et al. 2016; Kitamura et al. 2019; Alkhateeb et al. 2016), only a few studies have evaluated its effectiveness in a collaborative context. An extension of KB for peer-to-peer learning, the RKB, allows students to generate and exchange ideas with a partner before co-construction of a concept map. Learning activities during the RKB session consists of three main parts, i.e., individual map building, individual map reconstruction by partners, and difference map discussion (Wunnasri et al. 2018a). Initial studies conducted by Wunnasri et al. (2018a); Wunnasri et al. (2018b) find that the $\mathrm{KB}$ approach promoted more exploratory talk during group discussion and assisted group members to develop similar understanding, based on their individual first and post hoc maps. Those studies do not, however, take into account how individual knowledge 
is elaborated while constructing a collaborative map as an artifact that represents group consensus and shared understanding.

When RKB was put into practical use for collaborative concept mapping in a Linear Algebra class, almost all groups produced a high-quality collaborative map and there was an association between difference map visualization and individual-to-group-score gain (Sadita et al. 2018). The same study presents how group maps changed according to the KB visualization of different links; however, it did not investigate how individual differences in prior knowledge in each group may influence collaborative-learning effectiveness (e.g., transfer of knowledge, lost knowledge, group product) and the students' feelings about the learning process itself. This investigation is needed to draw a comprehensive understanding of the effectiveness of the $\mathrm{KB}$ approach, as well as to provide suggestions for practitioners who want to apply the KB method in the classroom environment.

The present study aims to identify the effect of differences in group composition on learning effectiveness in two dimensions-i.e., interaction between group members and group achievement-based on measurements proposed by some previous studies (Khamesan and Hammond 2004; Stoyanova and Kommers 2002). To determine the homogeneity of group composition, we used the knowledge convergence measurement defined by (Weinberger et al. 2007), which distinguishes group knowledge equivalence and shared knowledge (Khamesan and Hammond 2004; Stoyanova and Kommers 2002). Furthermore, learners' perceptions of the learning activities were evaluated to find out their affective responses to different group compositions. The following research questions guide our study:

(a) What are the overall patterns of knowledge transfer from individual-to-group representation?

(b) Does similarity of knowledge affect students' learning effectiveness in the two dimensions (i.e., interaction of individual members and group level), and, if so, to what extent?

(c) Does similarity of knowledge affect the experiences of participants in the study, and, if so, to what extent?

\section{Method}

\section{Participant characteristics}

The study was conducted in a Linear Algebra class for first year Computer Science students in a public university in Indonesia. The participants consisted of 42 students, of whom $71 \%$ were men. The subject aimed to provide students with tools for problem solving and mathematical thinking, especially in pattern finding and abstraction (Junus et al. 2014). In line with these goals, class activities mainly adopted student-centered and social-constructivist learning theories. The topics covered during the 16-week semester included linear equations, matrix algebra, vector space, inner product space, eigenvectors and eigenspace, and linear transformation and its applications for computation.

For the experiment, the teacher selected the topics of General Vector Spaces and Inner Product Spaces. The notion of vector as an element of a vector space was a new concept to most of the students, since they had previously studied vectors only as objects with both magnitude and direction. The accommodation of prior concepts within a new context remains a challenge for the teacher. It was therefore necessary to apply active learning 
methods, e.g., the use of concept maps in which students could draw their new conceptual knowledge and discuss it with their learning partners. The students were familiar with concept mapping activities, since the teacher had previously drawn schemata to show the relationships between concepts or asked the students to construct their own maps after completing a learning topic. The teacher detected students' misconceptions through their concept maps (Junus 2018).

\section{Experimental settings}

The study implemented a single-group design where all participants received the same treatment and were observed in their natural settings. Before conducting the experiment, an introductory explanation and some relevant learning resources on the topics were delivered to the classroom and through a learning management system. The teacher determined some essential concepts (nodes) $(n=15)$ to be included in the map, i.e., Inner Product (IP) Space, Vector Space (VS), IP function, domain: $V \times V$, co-domain: $R$, additivity axiom, homogeneity axiom, positivity axiom, symmetry axiom, vector, orthogonal projection, distance between two vectors, length of a vector, angle between two vectors, and directed line segment. By having the nodes provided, the students were able to identify common references and maintain shared focus during discourse. Hence, they were asked to draw relationships (links) among the nodes and define the linking words to form a concept map.

The experiment was administered in a computer laboratory for around $2 \mathrm{~h}$ and was divided into two main phases: individual and collaborative. First, each participant built their own map using a computer. After submitting the map online, they were requested to construct another map based on the nodes and links (components) from their partner's first map. During the second, collaborative phase, the KB system visualized the similarities and differences between each individual's first map and the corresponding partner's map. The students discussed the ideas facilitated by the visualization, and, finally, they were asked to create an integrative group map together. Figure 1 illustrates the activities of participants during the experiment. They worked in close proximity during individual map construction, then built the group map using just one computer.

The participants chose their partners beforehand, according to their preferences. Group randomization was not applied to encourage active participation and open communication. For the analysis, we clustered groups based on the similarity of their prior knowledge and shared knowledge about the task. The teacher attended the experiment and gave instructions, but did not intervene in students' discussions. She provided feedback to participants, based on their individual and group maps, since it was necessary to clarify their understanding, but only did this several days after the completion of the experiment. We also conducted a survey to capture learners' perceptions of the activities themselves.

\section{Variables and measurements}

There are three variables in this study: similarity of knowledge, learning effectiveness, and learners' affective responses. Similarity of knowledge was determined based on the students' mid-term scores and their individual (first) maps; learning effectiveness was measured from the collaborative (final) maps and the similarity of contents between the individual and collaborative maps; the affective responses of the learners were captured 


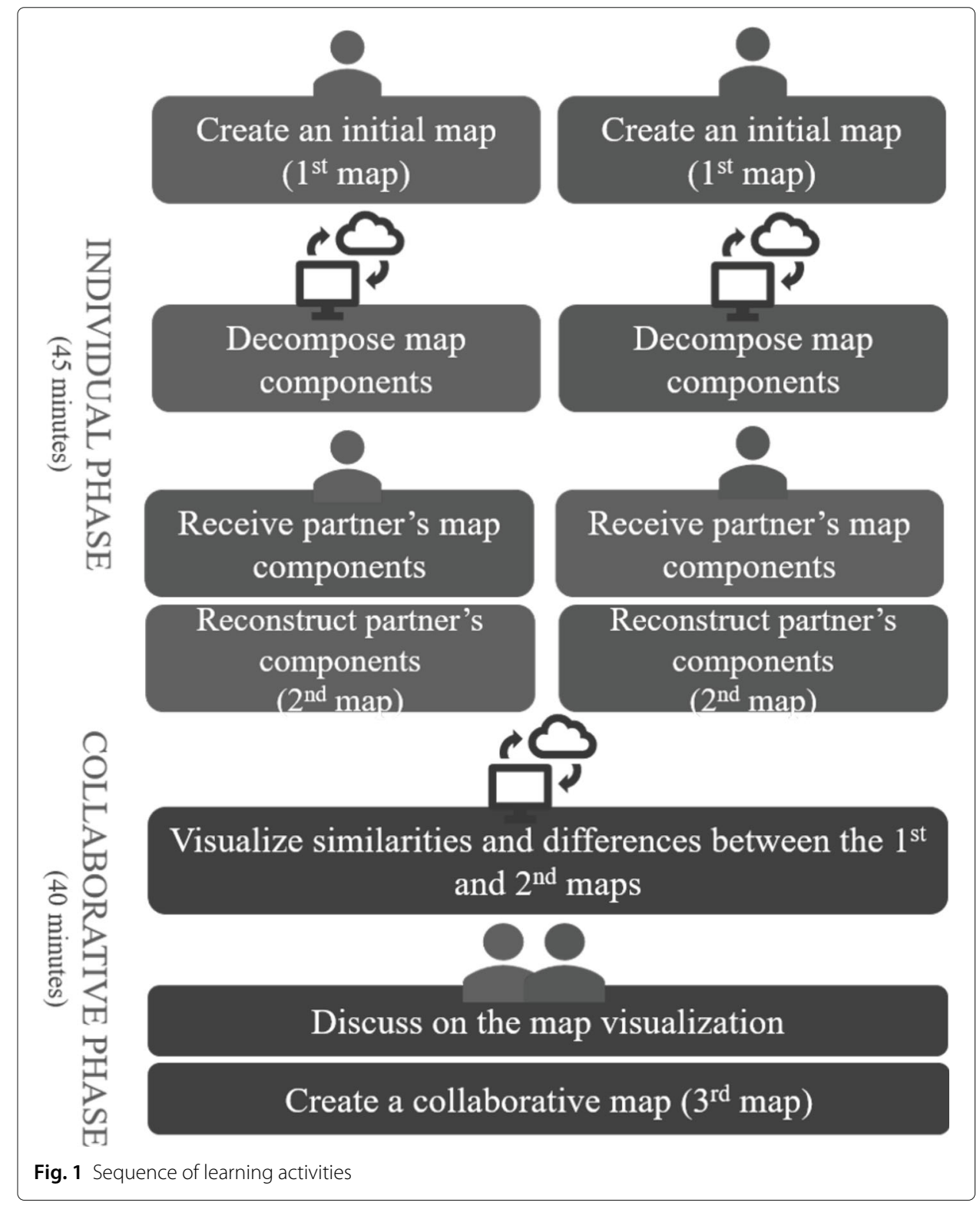

through a questionnaire. Figure 2 depicts the relationships between all variables as well as the corresponding data source.

\section{Similarity of knowledge}

Weinberger, Stegmann, and Fischer conceptualize knowledge convergence as knowledge equivalence and shared knowledge, which can be evaluated prior to, during, or after collaboration (Weinberger et al. 2007). In order to identify similarity of knowledge within each group, we used two types of measurements: prior-knowledge equivalence and shared knowledge. Knowledge equivalence refers to learners in a group possessing a similar degree of knowledge related to a specified subject, regardless of the specific concepts constituting knowledge content (Weinberger et al. 2007), while shared knowledge alludes to the knowledge of specific concepts that learners within a group have in common (Weinberger et al. 2007). 


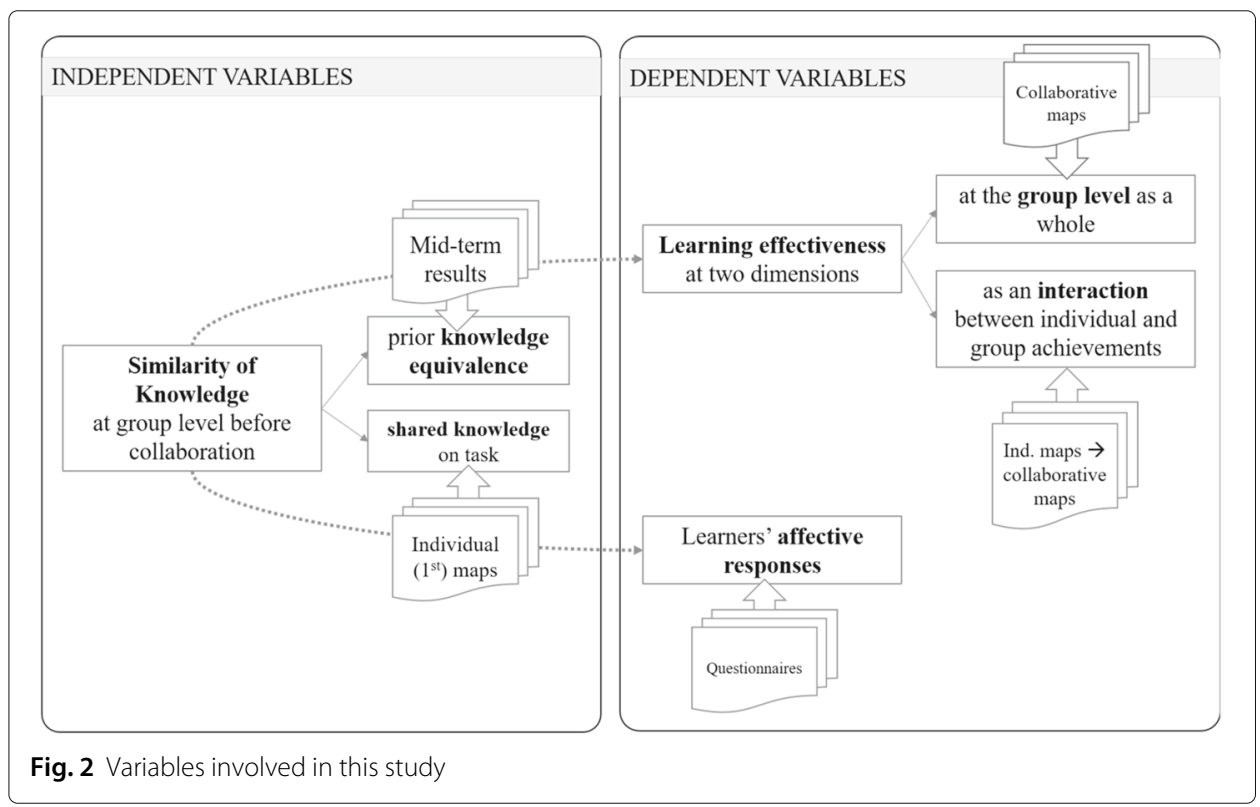

The prior-knowledge equivalence scores were calculated from the results of a midterm test conducted a few days before the experiment. The questions in the test covered essential introductory materials required to understand the main topic in the concept map, but did not include the conceptual knowledge that could be drawn in a map form, such as the relationships between concepts. Measures of dispersion were used to analyze differences in prior knowledge, as in a prior study (Weinberger et al. 2007). First, individual mid-term tests were evaluated by the teacher. Second, the standard deviation between the scores and the average scores in each group was calculated. Last, the standard deviation was divided by the mean score to measure the coefficient of variation as a prior-knowledge-equivalence score.

We assessed shared knowledge quantitatively from the individual maps using the approach proposed by Weinberger et al. (2007). First, the teacher defined the essential information to be included in the maps. Then, she listed all possible and common substructures from all student-generated maps. A substructure may consist of two or more connected nodes (concepts) that convey only one essential piece of information (see Table 1). Variation in substructures was also deemed acceptable, depending on the linking words written by the students. Second, the teacher marked whether a student's map exhibited any of the essential information or not. A maximum of seven important substructures was expected to appear in the maps. Third, if a pair of learners shared the ability to apply a specific concept, we added a shared-prior-knowledge score of 1 . Finally, we normalized the score by dividing it by the group mean value. In addition, we counted the number of unshared substructures at the individual level to identify information possessed only by a single member.

Table 2 provides a sample of knowledge distribution in a group. Following the above procedure, the individual-knowledge scores of students A and B in group 01 were 3 and 2 , respectively, based on the number of correct substructures, resulting in a mean of 2.5. Group 01 achieved a shared-knowledge value of 2 because both members were able 
Table 1 Seven essential pieces of information included in the map and its possible substructure

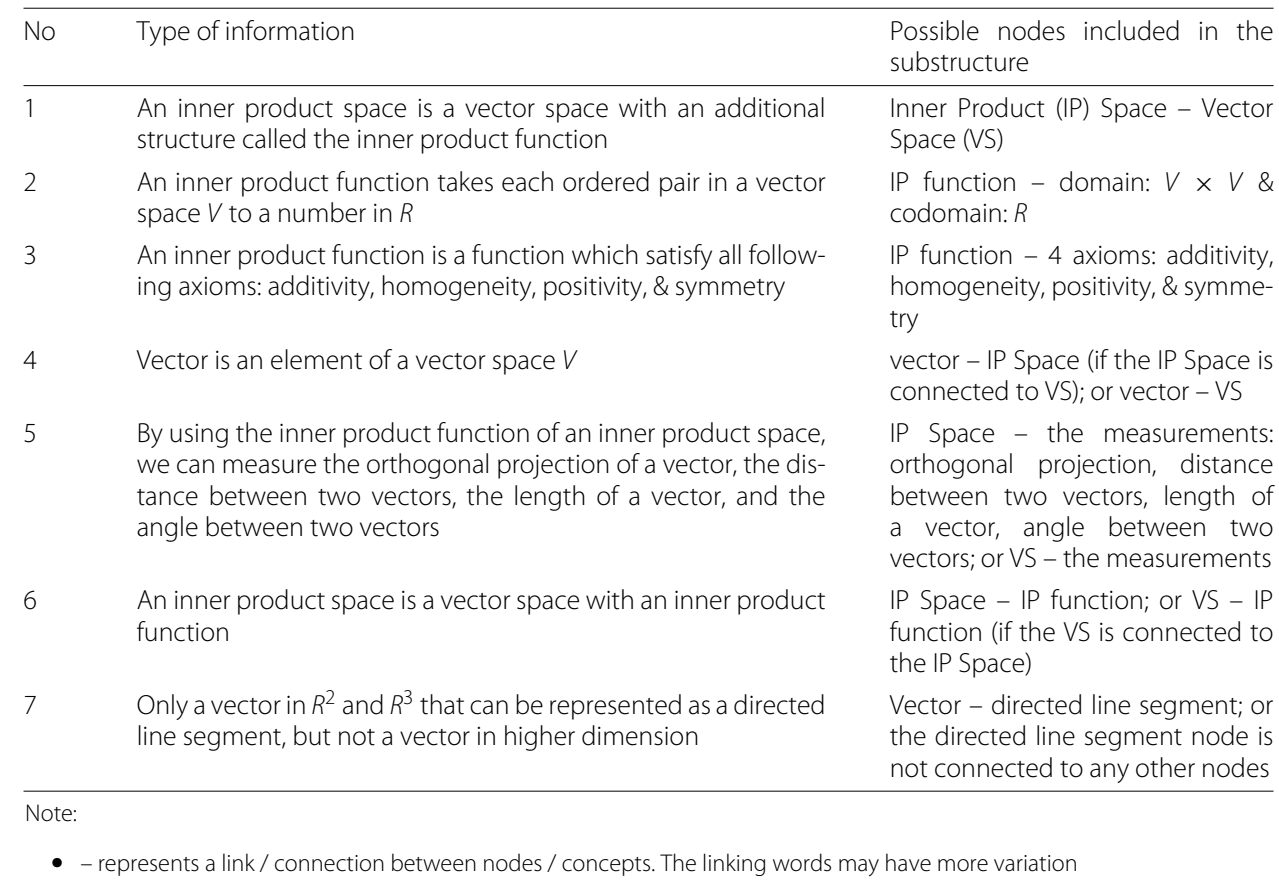

to draw the first and the fourth substructures correctly. Consequently, the normalized shared-knowledge score of this group was $2 / 2.5$ (i.e., 0.8 ).

The normalized prior-knowledge-equivalence score and shared-knowledge score were applied to categorize the group. Groups with normalized prior-knowledge-equivalence scores of less than 0.2 were categorized as high-knowledge-equivalence groups, and groups with normalized shared-knowledge scores of more than 0.7 were categorized as high-shared-knowledge groups. The prior-knowledge-equivalence scores provided the different levels of individual performance on prior relevant topics, while the sharedknowledge scores were more specific to knowledge related to the task itself.

\section{Learning effectiveness measurements}

To measure learning effectiveness, this study employed collaborative concept mapanalysis methods proposed by Khamesan and Hammond (Khamesan and Hammond 2004), which extend the initial works of Stoyanova and Kommers (2002). Khamesan and Hammond divide learning effectiveness into three levels: the level of individual learning, the level of a group as a whole, and the level of interaction between individual and group. This scoring system achieved a high inter-rater reliability score, with correlations

Table 2 Sample of knowledge distribution in a group

\begin{tabular}{|c|c|c|c|c|}
\hline No & Substructures & $\begin{array}{l}\text { Student } \\
\text { A's map }\end{array}$ & $\begin{array}{l}\text { Student } \\
B^{\prime} \text { s map }\end{array}$ & $\begin{array}{l}\text { Group } \\
\text { map }\end{array}$ \\
\hline 1 & Inner Product (IP) Space - Vector Space (VS) & O & O & O \\
\hline 2 & IP function - domain: $V x V \&$ codomain: $R$ & $x$ & $x$ & O \\
\hline 3 & IP function - 4 axioms & O & $x$ & o \\
\hline 4 & Vector - IP Space or VS & O & O & $x$ \\
\hline
\end{tabular}

Note: $\mathrm{o}$ is the substructure was available and correct and $x$ is the substructure that was not available or incorrect 
between $r=.52$ and $r=.99$, for most of the categories. Since our collected data consists of both students' individual maps and the group map, we only evaluated effectiveness in two dimensions: at the group level as a whole and as an interaction between individual and group achievements. The following measures are used in this study (see Fig. 3):

- Individual-to-group transfer of shared knowledge $\left(T S K_{A B}\right)$ : the number of substructures shared by both individual maps and transferred to the collaborative map. The score was normalized with the number of shared substructures.

- Individual-to-group transfer of unshared knowledge $\left(T U K_{A(o r B)}\right)$ : the number of unshared substructures in each individual map and transferred to the collaborative map. The score was normalized with the number of unshared substructures.

- Individual-to-group transfer $\left(T K_{A B}: T S K_{A B} \cup T U K_{A} \cup T U K_{B}\right)$ : the total number of transferred substructures from individual maps to the collaborative map. The score was normalized with the number of shared and unshared substructures.

- Lost knowledge $\left(L K_{A B}:\left(I K_{A} \cup I K_{B}\right) \backslash T K_{A B}\right)$ : the number of individual substructures not transferred from individual maps to the collaborative map.

- Group creativity $\left(N K_{A B}\right)$ : the number of new substructures in the collaborative map that were not included in both individual maps. The score was normalized with the number of unknown substructures.

- Group achievement $\left(G K_{A B}\right)$ : the number of substructures in the collaborative map. The score was normalized with the maximum number of possible substructures.

After normalization, each score interval is between 0 and 1 .

Based on the sample of knowledge distribution depicted in Table 2, substructures (1) and (4) were the shared knowledge about the task of group 01, while substructure (3) was the unshared knowledge of student B, and substructure (2) was the unknown substructures of group 01 (ignorance). During collaboration, the students wrote substructures (1) to (3) correctly, so we regarded those substructures as group knowledge. Specifically, substructure (1) was considered as the individual-to-group transfer of shared knowledge, substructure (2) was categorized as new knowledge, and substructure (3) was categorized as the individual-to-group transfer of unshared

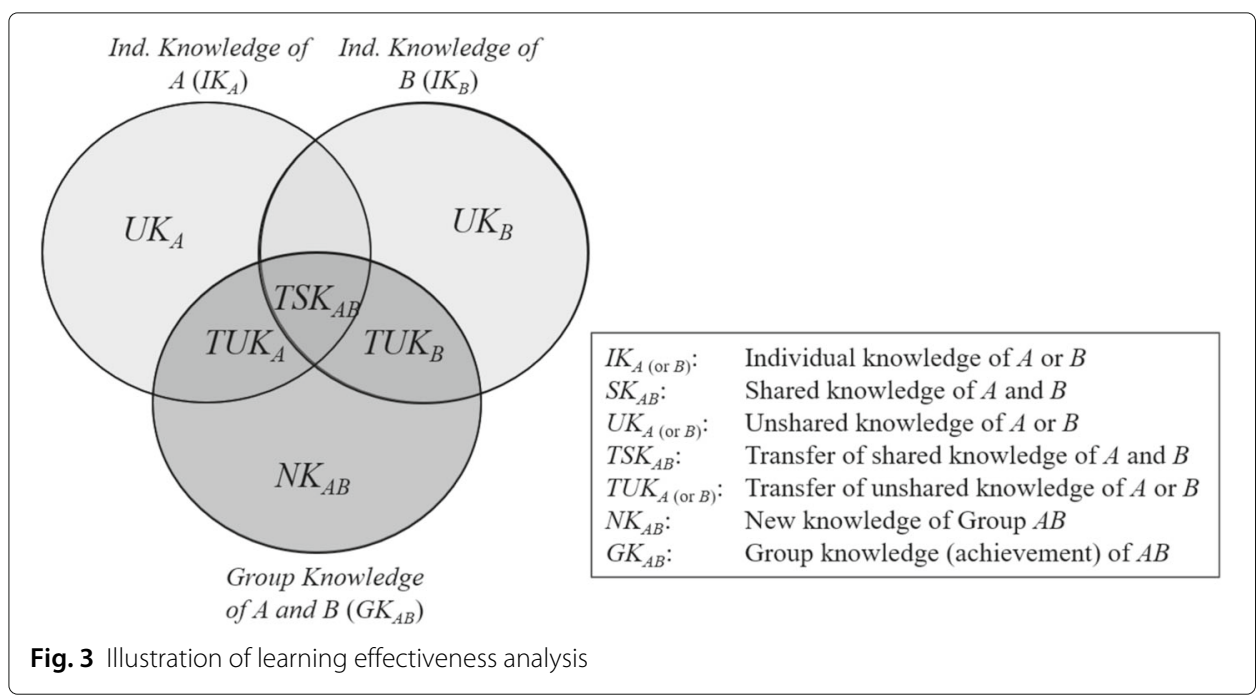


knowledge. As group 01 members did not write substructure (4), it was categorized as lost knowledge.

\section{Learners' affective responses}

We conducted a survey to capture the experiences of learners while participating in the experiment. The questionnaire consisted of 15 closed-ended items related to attractiveness, stimulation, and perspicuity subscales, which were adapted from an Indonesianlanguage version of a user-experience questionnaire (Santoso et al. 2016). The students rated the items on a Likert scale (from 1 to 7 ). Six open-ended questions were asked to capture the positive and negative experiences of learners at every step of the collaborative learning activities. All questionnaire items had been face-validated by the teacher before distribution to the students. Cronbach's alpha coefficients were $0.74,0.84$, and 0.77 for attractiveness, stimulation, and perspicuity subscales, respectively, showing good internal consistency.

\section{Results}

\section{Overall patterns of knowledge transfer}

During the first phase of the experiment, $82 \%(n=120)$ of the essential substructures were written in the individual maps. Fifty-five percent of those written substructures are shared knowledge (Fig. 4). As much as $92 \%$ of the shared and unshared knowledge is also seen in the collaborative maps, the remainder becoming non-transferred (lost) knowledge. Almost all shared knowledge is transferred to the collaborative map, while the percentage of neglected unshared knowledge is $15 \%(n=8)$ of total unshared knowledge. Fourteen groups extended their group maps with new information (substructures) that did not exist in the individual maps $(n=8)$. The amount of unknown information (ignorance) in the collaborative maps decreased, from 18 to $13 \%$.

\section{Learning effectiveness at the group and interaction level}

Figures 5 and 6 display the distribution of knowledge transfer and group creativity (new substructures) among different conditions regarding prior-knowledge-equivalence and shared knowledge on the individual concept maps. Since the data do not follow a normal distribution, only median and range values are presented in the figures. The amount of shared and unshared knowledge transfer from all groups in all conditions remained

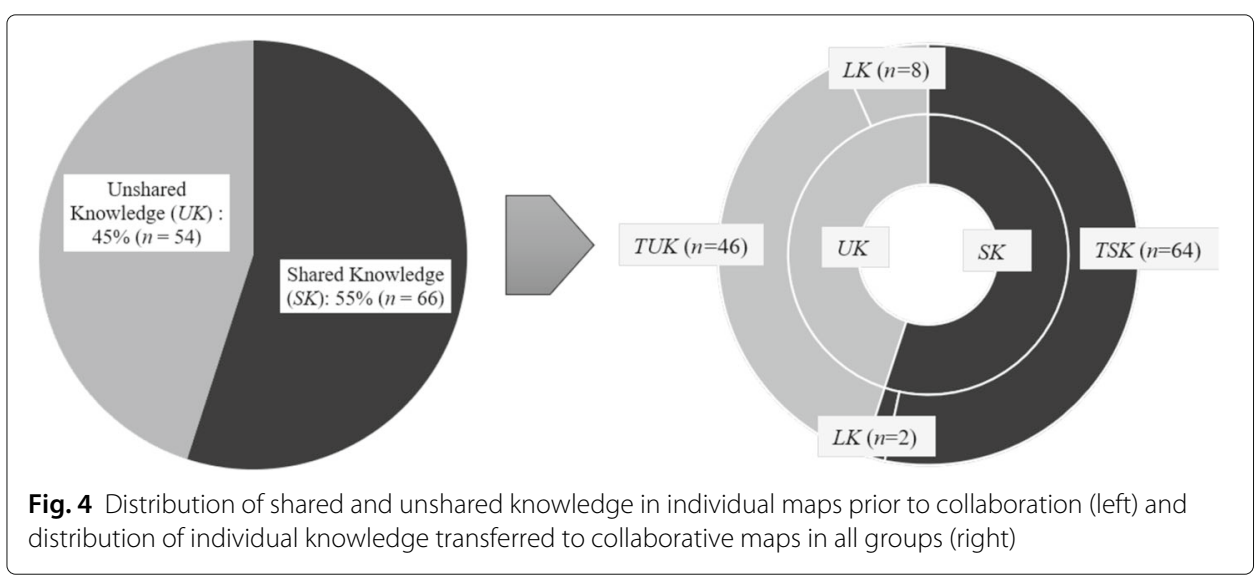



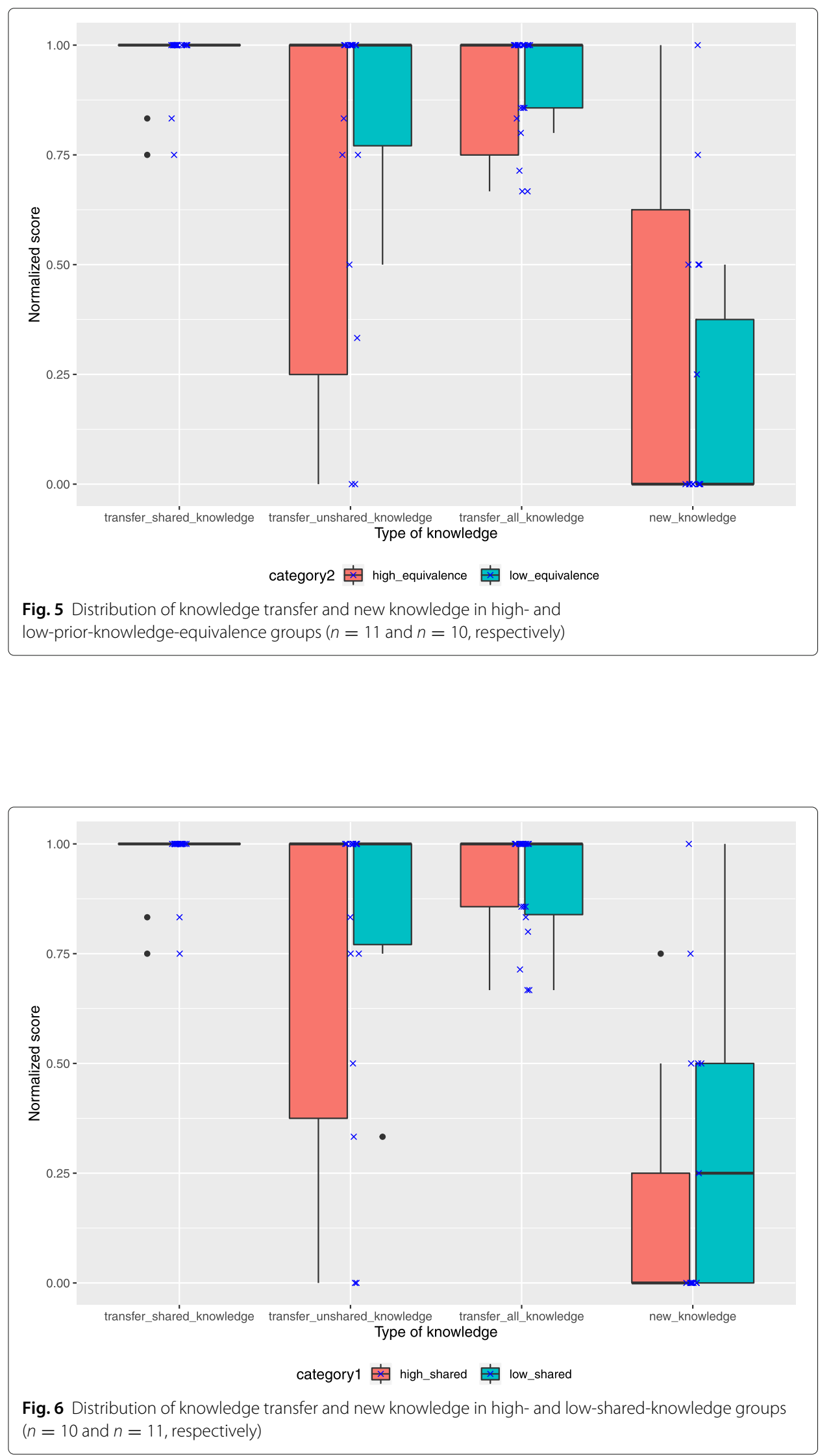
at the same level (similar median values), with differences in score distribution. The high-knowledge-equivalence groups have quite different scores, regarding transfer of knowledge, in comparison with the low-knowledge-equivalence groups. A similar trend is seen in the high- and low-shared-knowledge groups, in terms of their transfer of shared and unshared knowledge. In general, the individual-to-group transfer of knowledge score in high- and low-shared-knowledge conditions exhibits the same median value and similar distribution.

We also investigated whether individual knowledge about the task affects group tendency to transfer unshared knowledge, by calculating the correlation between individual map score and normalized score for individual unshared-knowledge transfer. Results of the Pearson correlation indicate that there is no association between individual map score and amount of unshared-knowledge transfer $(r(22)=-.060, p=.78)$.

Based on the knowledge-equivalence scores, the group creativity scores in both conditions show similar median values, though the distribution is different. The high-knowledge-equivalence groups show more variation of group creativity score than the low-knowledge-equivalence groups. However, the low-shared-knowledge groups have higher new knowledge scores than high-shared-knowledge groups. The 14 groups who have new knowledge are similarly distributed in each condition ( $n=7$ each).

All collaborative map scores are in the range of $75-100$ for all conditions $(M=90, \mathrm{SD}=$ $7.31)$ and are higher than individual map scores $(M=72.2, \mathrm{SD}=25.5)$. On average, the low-knowledge-equivalence groups received 91.17 collaborative map scores (Fig. 7). Some samples of the collaborative maps are illustrated in Figs. 8 and 9.

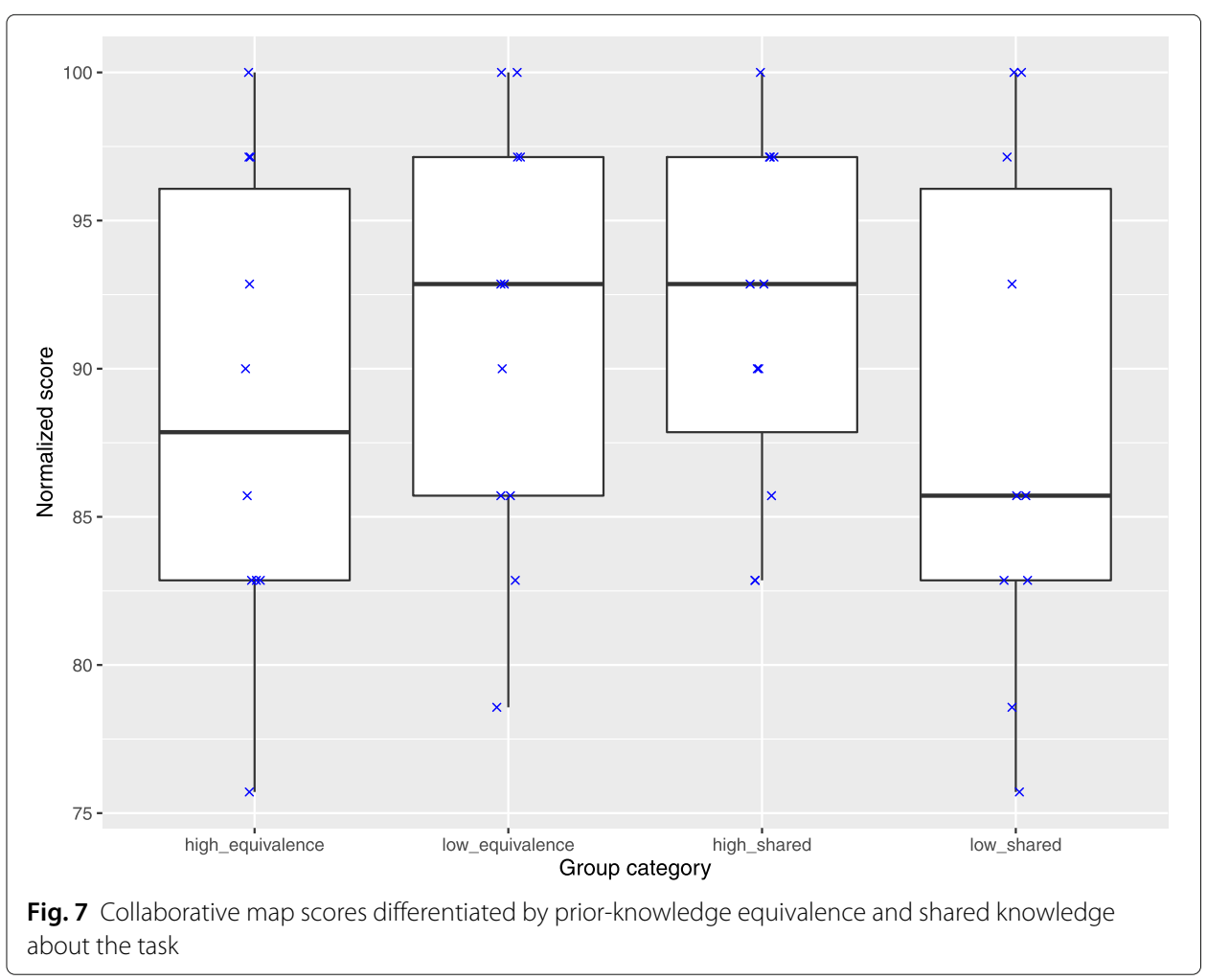




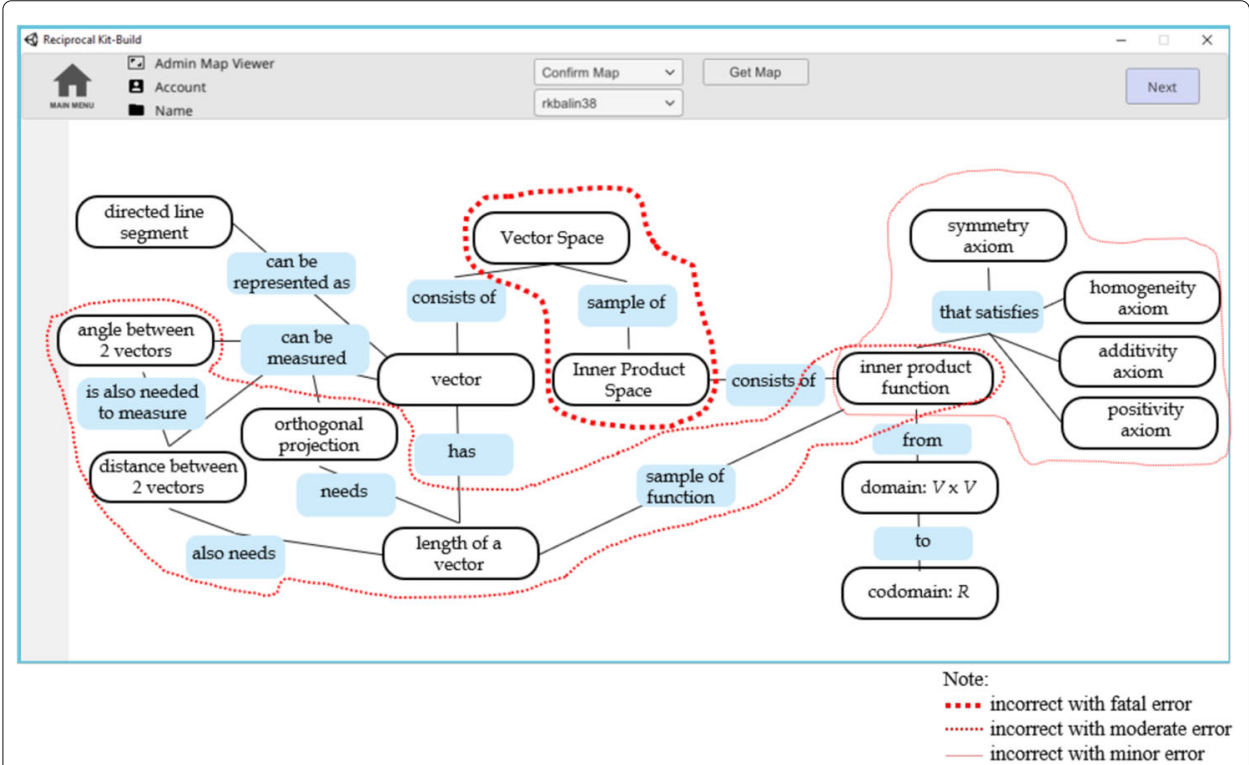

Fig. 8 Sample of a low-quality collaborative map with the score of 75.71. Some sub-substructures were written incorrectly. The group is belong to high-prior-knowledge-equivalence and low-shared-knowledge condition

\section{Learners' affective responses}

Figure 10 presents the distribution of the affective response scores among groups with different shared-knowledge scores. A Kruskal-Wallis rank-sum test indicates that there is a significant difference between the groups with higher similarity scores and lower similarity scores $(H(13)=56.8, p<.001)$. However, these differences, though significant, are small, which denotes that the learners in heterogeneous groups do experience positive feelings towards the activities, albeit less positive than those of learners in homogeneous groups. The stimulation subscale receives the highest rating, followed by the

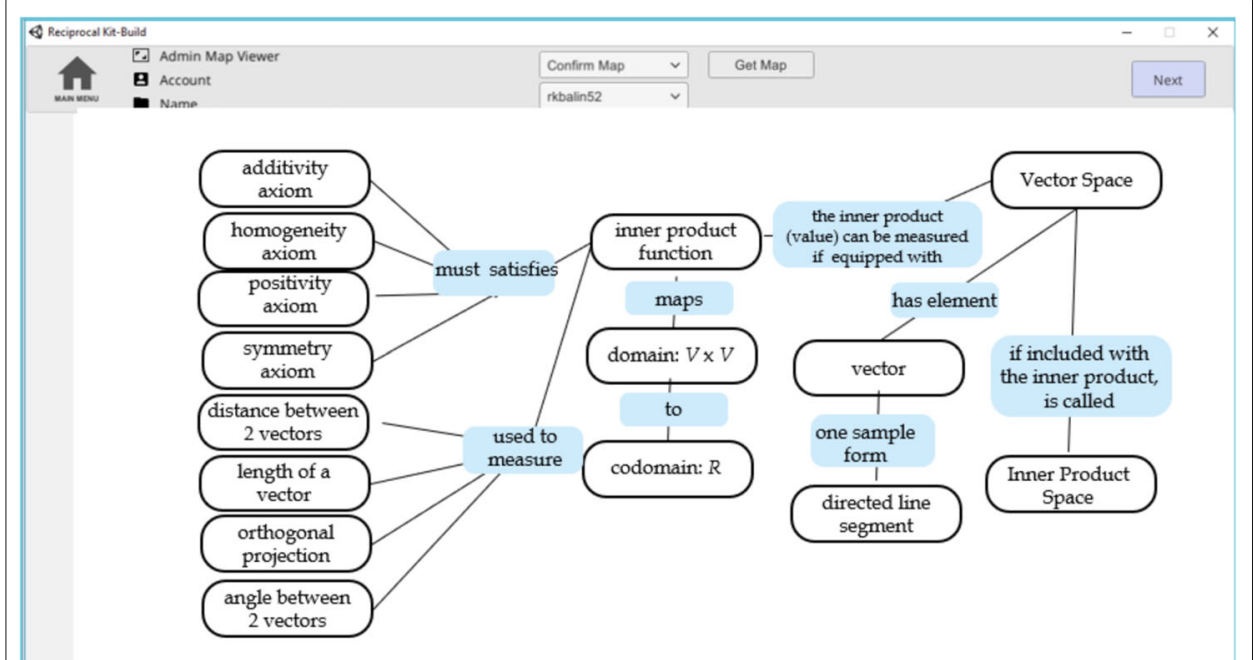

Fig. 9 Sample of a high-quality collaborative map with the score of 100. The group belongs to low-prior-knowledge-equivalence and low-shared-knowledge condition 


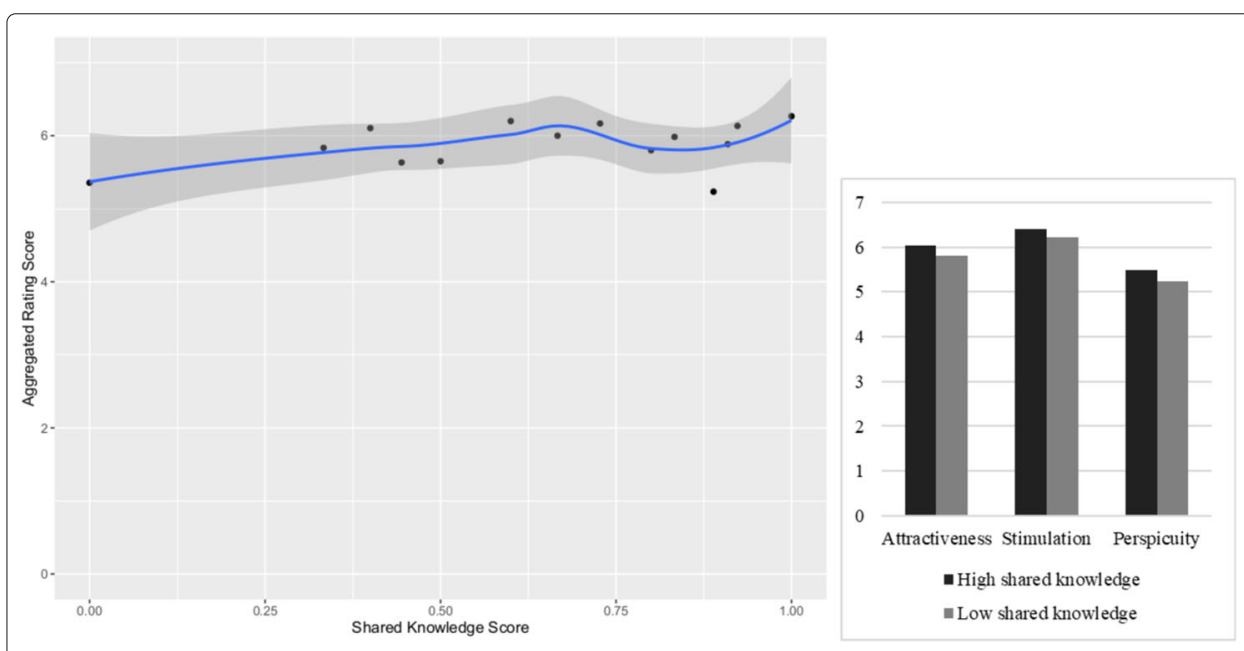

Fig. 10 Distribution of affective responses across different shared-knowledge scores

attractiveness and perspicuity subscales, respectively. From the open-ended questions, we found that some participants in both homogeneous and heterogeneous groups reported comparable on-task difficulties concerning dissimilarities of ideas or opinions, i.e., "Difficult to read when the number of visualized differences is too many $(n=6)$," "It was hard to read or understand the difference map $(n=2)$," "It was difficult to integrate different opinions in order to reach a (group) consensus or determine which one is the correct representation $(n=5)$," and "The use of ambiguous links makes it hard to select the most suitable relation between two concepts $(n=1)$."

\section{Discussion}

Collaborative concept mapping using the RKB approach allows learners to represent and manipulate individual cognitive structures and lets partners provide feedback after initial map reconstruction and difference map visualization. This activity provides an active means to review individual maps and to elicit new information. Access to distributed cognitive resources gained through reviewing learners' individual maps positively influenced the broadness of group solutions to problems (Stoyanova and Kommers 2002). Consistently, our findings show that the amount of essential knowledge, which each group should have possessed, was increasing while students took part in the activities. The process of knowledge acquisition and creation through direct interaction had an impact on group-learning effectiveness (Stoyanova and Kommers 2002).

\section{$R Q$ (a): What are the overall patterns of knowledge transfer from individual-to-group} representation?

We found that both types of knowledge (shared and unshared) were highly transferred to group solutions, with a rate of $92 \%$. In contrast, some previous studies report that groups often abandon unshared knowledge or resources (Fischer and Mandl 2002; Gracia-Moreno et al. 2017). This indicates that this approach has the potential to create awareness of others' understanding regardless of the type of knowledge. The weak correlation between individual map scores and the normalized transfer of unshared-knowledge score demonstrates that students were able to detect important substructures without 
giving undue consideration to who was the source of information during the collaborative phase. For instance, a student who had a lower individual map score than their partner could transfer their unshared knowledge, while the one with the higher individual score might unable to convey their unshared knowledge. Another implication is that the students tended not to merely follow particular group members. They acknowledged their partners' perspectives and considered others' different understandings.

\section{$R Q$ (b): Does similarity of knowledge affect students' learning effectiveness in the two} dimensions (i.e., interaction of individual members and group level), and, if so, to what extent?

The amount of knowledge transfer from individual to group solutions represents learning effectiveness as an interaction of individual-to-group knowledge. The results show that the amount of knowledge transfer was considerably high for all group conditions. Although there are some differences regarding the scores for knowledge transfer, for both shared and unshared knowledge, the divergence in prior knowledge or shared knowledge about the task in each group did not significantly influence the median scores for knowledge transfer (Figs. 5 and 6). The distribution of transfer scores in the homogeneous groups has more variation than in the more heterogeneous ones. This implies that the heterogeneous groups had a higher tendency to transfer individual knowledge into group solutions. It is also interesting to note that some groups, that categorized as homogeneous groups, did not transfer all of their individual shared knowledge. Further investigation of their group processes would be needed to reveal the problems for these specific groups.

The homogeneous groups, based on their prior-knowledge equivalence, demonstrated lower achievements than the heterogeneous groups (Fig. 7). Meanwhile, the groups that were more homogeneous in terms of their shared knowledge achieved higher scores than the other groups. Despite this, the map scores for groups of different composition were not significantly different. Since the knowledge-equivalence score was based on prior knowledge, the low-equivalence groups might have broader perspectives on some previous topics that were not directly connected to the mapping task. In contrast, the shared-knowledge scores were measured from the maps themselves. Therefore, the low-shared-knowledge groups might initially attempt to resolve conflicts over certain concepts, while the high-shared-knowledge groups could focus directly on building better maps.

\section{$R Q$ (c): Does similarity of knowledge affect the experiences of participants in the study, and, if so, to what extent?}

The affective responses of the groups demonstrate that learners in higher-sharedknowledge groups are slightly more positive than those working in low-shared-knowledge conditions. Participants under both conditions display similar patterns: they thought that our activities were stimulating and attractive rather than perspicuous. Difficulties appeared when they faced differences in ideas or perspectives and needed to resolve those conflicts in order to reach a single group solution. Although pursuing conflict resolution is essential for conceptual change and advancement of knowledge in collaborative learning (Chan et al. 1997; Roschelle 1992; van Boxtel et al. 2002), the learners responded negatively. This might affect their motivation for participating in collaborative activities. Further studies on how computer-based visualization can be utilized to assist learners during conflict-oriented and integration-oriented consensus building are indispensable. 


\section{Limitations and some potential future works}

Several limitations to this preliminary study need to be acknowledged. The current study has evaluated the learning effectiveness of collaborative concept mapping activities only in two different dimensions (i.e., the level of the group as a whole and the level of interaction between individual and group). We have not investigated their effectiveness at the level of individual learning since there is a lack of evidence related to individual performance after collaboration. A prior study suggests that the level of convergence achieved during collaborative concept mapping may influence individual performance after collaboration (Gnesdilow et al. 2010). Since the amount of knowledge transfer during collaboration is significant, this approach has the potential to support learners in attaining learning effectiveness at the individual level. Furthermore, an evaluation of individual learning achievements after collaboration is necessary to get more comprehensive understanding of its effect at the individual level.

The concept mapping activity was conducted once during $2 \mathrm{~h}$ class session. It is insufficient to infer the generalizability of the results, so more experimental sessions during one term of study are strongly recommended. Further studies with a large number of participants from different subject areas are also necessary to identify the breadth of this approach. It would also be interesting in the future to compare the results of groups with reciprocal teaching activity and conventional collaborative concept mapping without the reciprocal cycle since the current study is a single group design without a comparison group.

\section{Conclusion}

In summary, the current study finds that, following the designated activities, learners are informed about their partner's understanding, whether such knowledge is shared or unshared. Furthermore, they have a greater tendency to elaborate it into group knowledge. Groups with high and low similarity of knowledge achieved similar learning effectiveness at the level of interaction between individuals and group as whole. Differences in group composition, based on similarity of prior knowledge or shared knowledge about the task, does not significantly differentiate the learning effectiveness. However, since the designated activities enabled tangible expression of individual knowledge structures, the amount of joint knowledge within the group may possibly affect group outcomes. Moreover, different opinions or perspectives on the task itself influence learners' overall experiences within a collaborative environment.

These findings enhance our understanding of the effect of the RKB approach for collaborative concept mapping across different group compositions. This investigation is also useful to provide suggestions regarding group formation for the practitioners who intend to apply the approach in their classroom. It also provides future direction to advance the RKB system, for example, by designing a computer-based visualization that would help students to resolve conflicts and reach a consensus. Though the students may acknowledge dissimilar perspectives from the partner's representation, integrating different ideas continues to be a challenge for them. 


\section{Acknowledgements}

There are no acknowledgments.

\section{Authors' contributions}

This study reported in this article is a part of the PhD project conducted by LS. TH is her main supervisor, and YH is her co-supervisor. An initial manuscript was written by LS. KJ and HBS have significant contribution to plan and prepare the materials for conducting the experiment, collecting the data, and reviewing the manuscript. PGFF helped to analyze the data and review the draft. Each named author has substantially contributed to conducting the underlying research. The authors read and approved the final manuscript.

\section{Funding}

This work was partially supported by the JSPS KAKENHI Grant Numbers $19 H 04227$ and 17 H01839.

\section{Availability of data and materials}

Data is available, but it is not applicable.

\section{Ethical approval and consent to participate}

Ethical approval is not applicable, but consent form to participate was obtained.

\section{Consent for publication}

Written consent form for publication was obtained.

\section{Competing interests}

The authors declare that they have no competing interests.

\section{Author details \\ ${ }^{1}$ Learning Engineering Laboratory, Department of Information Engineering, Hiroshima University, Hiroshima, Japan. \\ ${ }^{2}$ Digital Library and Distance Learning Laboratory, Faculty of Computer Science, Universitas Indonesia, West Java,} Indonesia.

\section{Received: 23 January 2019 Accepted: 3 May 2020}

Published online: 10 June 2020

\section{References}

Alkhateeb, M., Hayashi, Y., Rajab, T., Hirashima, T. (2016). Experimental evaluation of the KB-mapping method to avoid sentence-by-sentence map-building style in EFL reading with concept mapping. Information and Systems in Education, 15(1), 1-14.

Basque, J., \& Lavoie, M.-C. (2006). Collaborative concept mapping in education: major research trends, In Concept Maps: Theory, Methodology, Technology. Proc. of the Second Int. Conference on Concept Mapping. http://citeseerx.ist.psu.edu/ viewdoc/download?doi=10.1.1.103.1709\&rep=rep1\&type=pdf (pp. 79-86).

Beers, P.J., Boshuizen, H.P.A., Kirschner, P.A., Gijselaers, W.H. (2006). Common ground, complex problems and decision making. Group Decision and Negotiation, 15(6), 529-556. https://doi.org/10.1007/s10726-006-9030-1.

Chan, C., Burtis, J., Bereiter, C. (1997). Knowledge building as a mediator of conflict in conceptual change. Cognition and Instruction, 15(1), 1-40. https://doi.org/10.1207/s1532690xci1501_1.

Czerniak, C.M., \& Haney, J.J. (1998). The effect of collaborative concept mapping on elementary preservice teachers' anxiety, efficacy, and achievement in physical science. Journal of Science Teacher Education, 9(4), 303-320. https://doi. org/10.1023/A:1009431400397.

Engelmann, T., \& Hesse, F.W. (2010). How digital concept maps about the collaborators' knowledge and information influence computer-supported collaborative problem solving. International Journal of Computer-Supported Collaborative Learning, 5(3), 299-319. https://doi.org/10.1007/s11412-010-9089-1.

Engelmann, T., Kozlov, M.D., Kolodziej, R., Clariana, R.B. (2014). Fostering group norm development and orientation while creating awareness contents for improving net-based collaborative problem solving. Computer in Human Behavior, 37(C), 298-306. https://doi.org/10.1016/j.chb.2014.04.052.

Fischer, F., Bruhn, J., Gräsel, C., Mandl, H. (2002). Fostering collaborative knowledge construction with visualization tools. Learning and Instruction, 12(2), 213-232. https://doi.org/10.1016/S0959-4752(01)00005-6.

Fischer, F., \& Mandl, H. (2002). Facilitating knowledge convergence in videoconferencing environments: the role of external representation tools, In Proceedings of the Conference on Computer Support for Collaborative Learning: Foundations for a CSCL Community, CSCL '02. https://dl.acm.org/doi/10.5555/1658616.1658754 (pp. 623-624).

Gnesdilow, D., Bopardikar, A., Sullivan, S.A., Puntambekar, S. (2010). Exploring convergence of science ideas through collaborative concept mapping, In The 9th International Conference of the Learning Sciences, ICLS'10, vol. 1. https://dl. acm.org/doi/10.5555/1854360.1854449 (pp. 698-705).

Gracia-Moreno, C., Cerisier, J.-F., Devauchelle, B., Gamboa, F., Pierrot, L. (2017). Collaborative knowledge building through simultaneous private and public workspaces, In European Conference on Technology Enhanced Learning. https://doi. org/10.1007/978-3-319-66610-5_61 (pp. 553-556).

Hay, D., Kinchin, I., Lygo-Baker, S. (2008). Making learning visible: the role of concept mapping in higher education. Studies in Higher Education, 33(3), 295-311. https://doi.org/10.1080/03075070802049251.

Hirashima, T. (2019). Reconstructional concept map: automatic assessment and reciprocal reconstruction. International Journal of Innovation, Creativity and Change, 5, 669-682. 
Hirashima, T., \& Hayashi, Y. (2016). Educational externalization of thinking task by Kit-Build method, In Human Interface and the Management of Information: Applications and Services. https://link.springer.com/chapter/10.1007/978-3-31940397-7_13 (pp. 126-137).

Hirashima, T., Yamasaki, K., Fukuda, H., Funaoi, H. (2015). Framework of kit-build concept map for automatic diagnosis and its preliminary use. Research and Practice in Technology Enhanced Learning, 10(1), 17. https://doi.org/10.1186/s41039015-0018-9.

Ifenthaler, D. (2010). Relational, structural, and semantic analysis of graphical representations and concept maps. Educational Technology Research and Development, 58(1), 81-97. https://doi.org/10.1007/s1 1423-008-9087-4.

Jeong, H., \& Chi, M.T.H. (2007). Knowledge convergence and collaborative learning. Instructional Science, 35(4), 287-315. https://doi.org/10.1007/s11251-006-9008-z.

Jeong, H., \& Hmelo-Silver, C.E. (2016). Seven affordances of computer-supported collaborative learning: how to support collaborative learning? How can technologies help? Educational Psychologist, 51(2), 247-265. https://doi.org/10.1080/ 00461520.2016 .1158654$.

Johnson, D.W., \& Johnson, R.T. (1987). Learning together and alone: cooperative, competitive, and individualistic learning, 2nd edn. New Jersey: Prentice-Hall, Inc.

Junus, K. (2018). Assessing students' mathematical misconceptions through concept maps and online discussion transcripts: inner product spaces, In The 26th International Conference on Computers in Education (ICCE 2018). http:// icce2018.ateneo.edu/wp-content/uploads/2018/12/C7-11.pdf (pp. 772-777).

Junus, K., Sadita, L., Suhartanto, H. (2014). Social, cognitive, teaching, and metacognitive presence in general and focus group discussion: case study in blended e-learning linear algebra class, In 2014 IEEE Frontiers in Education Conference (FIE) Proceedings. https://doi.org/10.1109/FIE.2014.7044247 (p. 6).

Khamesan, A., \& Hammond, N. (2004). Taxonomy of analysis levels of learning effectiveness in collaborative concept mapping, In Concept Maps: Theory, Methodology, and Technology. Proceeding of 1st International Conference on Concept Mapping (CMC), Spain, vol. 2. https://pdfs.semanticscholar.org/36e6/1dfcf67e940589b94fde88bddc97cd79f3da.pdf (pp. 231-234).

Kitamura, T., Hayashi, Y., Hirashima, T. (2019). Generation of Fill-in-the-Blank Questions from Concept Map and Preliminary Comparison between Multiple-Choice Task and Kit-Build Task. Journal of Information and Systems in Education, 18(1), 11-15. https://doi.org/10.12937/ejsise.18.11.

Novak, J.D., \& Gowin, D.B. (1984). Learning how to learn. Cambridge: Cambridge University Press. https://doi.org/10.1017/ CBO9781139173469.

Pailai, J., Wunnasri, W., Hayashi, Y., Hirashima, T. (2016). Ongoing formative assessment with concept map in proposition level exact matching, In The 24th International Conference on Computers in Education (ICCE 2016). https://doi.org/10. 13140/RG.2.2.22485.83680 (pp. 79-81).

Pailai, J., Wunnasri, W., Yoshida, K., Hayashi, Y., Hirashima, T. (2017). The practical use of Kit-Build concept map on formative assessment. Research and Practice in Technology Enhanced Learning, 12(1), 20. https://doi.org/10.1186/ s41039-017-0060-X.

Roschelle, J. (1992). Learning by collaborating: convergent conceptual change. Journal of the Learning Sciences, 2(3), $235-276$.

Roschelle, J., \& Teasley, S.D. (1995). The construction of shared knowledge in collaborative problem solving, In Computer Supported Collaborative Learning. https://link.springer.com/chapter/10.1007/978-3-642-85098-1_5 (pp. 69-97).

Sadita, L., Hirashima, T., Hayashi, Y., Wunnasri, W., Pailai, J., Junus, K., Santoso, H.B. (2018). Preliminary study on the use of Reciprocal Kit Build for collaborative learning, In The 26th International Conference on Computers in Education (ICCE 2018). http://icce2018.ateneo.edu/wp-content/uploads/2018/12/C2-03.pdf (pp. 133-142).

Santoso, H., Schrepp, M., Kartono, Y., Yudha, A., Priyogi, B. (2016). Measuring user experience of the student-centered e-learning environment. Journal of Educators Online, 13(1), 58-79. https://doi.org/10.9743/JEO.2016.1.5.

Stoyanova, N., \& Kommers, P. (2002). Concept mapping as a medium of shared cognition in computer-supported collaborative problem solving. Journal of Interactive Learning Research, 13(1), 111-133.

Suthers, D.D. (2006). Technology affordances for intersubjective meaning making: a research agenda for CSCL. International Journal of Computer-Supported Collaborative Learning, 1(3), 315-337. https://doi.org/10.1007/s11412006-9660-y.

van Boxtel, C., van der Linden, J., Kanselaar, G. (2000). Collaborative learning tasks and the elaboration of conceptual knowledge. Learning and Instruction, 10(4), 311-330. https://doi.org/10.1016/S0959-4752(00)00002-5.

van Boxtel, C., van der Linden, J., Roelofs, E., Erkens, G. (2002). Collaborative concept mapping: provoking and supporting meaningful discourse. Theory Into Practice, 41(1), 40-46. https://doi.org/10.1207/s15430421tip4101_7.

Webb, N.M. (2009). The teacher's role in promoting collaborative dialogue in the classroom. British Journal of Educational Psychology, 79(1), 1-28. https://doi.org/10.1348/000709908X380772.

Weinberger, A., \& Fischer, F. (2006). A framework to analyze argumentative knowledge construction in computer-supported collaborative learning. Computers and Education, 46(1), 71-95. https://doi.org/10.1016/j. compedu.2005.04.003.

Weinberger, A., Stegmann, K., Fischer, F. (2007). Knowledge convergence in collaborative learning: concepts and assessment. Learning and Instruction, 17(4), 416-426. https://doi.org/10.1016/j.learninstruc.2007.03.007.

Wunnasri, W., Pailai, J., Hayashi, Y., Hirashima, T. (2018). Validity of Kit-Build Method for Assessment of Learner-Build Map by Comparing with Manual Methods. https://doi.org/10.1587/transinf.2017EDP7177, E101.D (pp. 1141-1150).

Wunnasri, W., Pailai, J., Hayashi, Y., Hirashima, T. (2018a). Reciprocal Kit-Build concept map: an approach for encouraging pair discussion to share each other's understanding. IEICE Transactions on Information and Systems, E101.D(9), 2356-2367. https://doi.org/10.1587/transinf.2017EDP7420.

Wunnasri, W., Pailai, J., Hayashi, Y., Hirashima, T. (2018b). Reciprocal Kit-Building of concept map to share each other's understanding as preparation for collaboration, In The 19th International Conference on Artificial Intelligence in Education. https://link.springer.com/chapter/10.1007/978-3-319-93843-1_44 (pp. 599-612). 
Yoshida, K., Osada, T., Sugihara, K., Nino, Y., Shida, M., Hirashima, T. (2013). Instantaneous assessment of learners' comprehension for lecture by using Kit-Build concept map system, In Human Interface and the Management of Information. Information and Interaction for Learning, Culture, Collaboration and Business. https://link.springer.com/ chapter/10.1007/978-3-642-39226-9_20 (pp. 175-181).

\section{Publisher's Note}

Springer Nature remains neutral with regard to jurisdictional claims in published maps and institutional affiliations.

Submit your manuscript to a SpringerOpen ${ }^{\circ}$ journal and benefit from:

- Convenient online submission

- Rigorous peer review

- Open access: articles freely available online

- High visibility within the field

- Retaining the copyright to your article

Submit your next manuscript at $\gg$ springeropen.com 